\title{
The Coronary Collateral Artery: The Prognostic Importance and Functional Relevance
}

\author{
Rachmat Ageng Prastowo a , Primasitha Maharany Harsoyo ${ }^{a}$, Hanestya Oky Hermawan ${ }^{\text {a }}$ \\ I Gde Rurus Suryawan ${ }^{\mathrm{a}}$ \\ aprimasitha.maharany.harsoyo-2020@fk.unair.ac.id \\ ${ }^{a}$ Cardiology and Vascular Medicine Department-Airlangga University Faculty of Medicine, 47 Prof. Dr. Moestopo, Surabaya-60286, Indonesia
}

\begin{abstract}
Coronary collateral artery (CCA) is an alternative source of blood supply to an ischemic myocardial region. It is generally believed that there is a beneficial effect of collaterals in patients with coronary artery disease (CAD). Recently, reliable methods have become available for the assessment of the adequacy of collateral flow. However, the debate regarding the importance of CCA in the different clinical settings continues. In this review article, we discuss about the functional relevance of CCA to provide an overview of its impact on the prognosis of patients with CAD.
\end{abstract}

Keyword: Coronary collateral circulation, coronary artery disease, coronary artery circulation

\section{Introduction}

Coronary collateral artery (CCA) is a physiological adaptation that functions naturally to restore blood flow to threatened myocardium by coronary artery stenosis or blockage (Seiler C. 2010). CCA connects the epicardial coronary arteries in individuals with and without coronary artery disease (CAD). CCA is capable of remodeling and also develops in the presence of epicardial coronary artery stenosis (Zhu H, et al. 2017).

A well-developed circulating CCA is thought to protect myocardial function by limiting the infarct area and increasing myocardial viability after temporary or permanent coronary obstruction in patients with CAD (Seiler C, et al. 2013). CCA circulation can be assessed by several methods, but the gold standard is the collateral flow index (CFI) measurement which involves the measurement of intracoronary pressure (Meier P, et al. 2013).

The functional role of circulating CCA is still a topic of debated today. However, a well-developed CCA circulation might be associated with a severe degree of coronary stenosis (Fujita M, Sasayama S. 2010). Recent studies on the beneficial effects of collateral presence have been widely discussed. A study conducted by Hirai T, et al. in 1992 regarding CCA reported that collateral growth induced by repeated episodes of angina contributed to the improvement of left ventricular function in patients with acute myocardial infarction.

Another study conducted by Meier P, et al. in 2007 examined the survival rate of patients with stable CAD who had well-developed coronary collateral flow. Using CFI measurement, Meier et al evaluated the functional status of expandable collaterals and their prognostic benefit in 845 patients who were followed for 10 years. They reported that cardiac arrest incidence was 4-times higher in patients with inadequate $\mathrm{CCA}(\mathrm{CFI}<0.25)$ compared with patients with adequate CCA (CFI > 0.25) (Meier P, et al. 2013). 
In individuals with ST-elevation Myocardial Infarction (STEMI), a relevant protective role of collaterals can be observed in non-expanding infarct size, preserved cardiac function after acute infarction, and decreased aneurysm formation after ventricular infarction (Zhu H, et al. 2017). Based on this background, we compiled this literature review to discuss further assessment of CCA function to provide an overview of its benefits and prognosis for patients with CAD.

\section{CCA formation development}

The mechanism of CCA formation is influenced by mechanical and chemical processes through several stages. Depending on the initial trigger, the growth of blood vessels in adult organisms occurs through two main processes: angiogenesis and arteriogenesis. Angiogenesis is induced by hypoxia and will generate new capillaries, while arteriogenesis is induced by mechanical processes, most notably fluid shear stress (FSS), which represents remodeling of preexisting arterio-arteriolar anastomoses into fully developed and functional arteries. Mechanical shear stress occurs because of pressure gradient difference due to occlusion. Arterial stenosis increases the pressure on the proximal of the occlusion and reduces the pressure on the distal vessels of the occlusion. An increase in pressure on the proximal of the occlusion will cause an increase in blood flow in the capillary bed before the occlusion site, leading to increase of shear stress (Fujita M, Tambara K. 2004).

This increase in blood flow allows blood to enter the existing collateral vessels and the resulting increased shear stress causes several changes in the capillary endothelium. The initial phase will be an increase in MCP-1, which attracts more monocytes to the proliferative area to convert them into macrophages (Figure 1). Macrophages play an important role in releasing cytokines and growth factors that are required for arteriogenesis. TNF- $\alpha$, which is released by macrophages, helps to establish the inflammatory environment necessary for collateral growth (Van RN, et al. 2001).

Although shear stress is considered to be the main arteriogenesis mechanism, it cannot be the sole solution because of the inability of fluid shear stress (FSS) to completely replace the conducting arteries. It has been found that FSS accounts for only 35-40\% of the maximum stenotic artery conduction. The explanation for this phenomenon could be found in the correlation between FSS and blood flow velocity as well as between FSS and blood vessel diameter (Schaper W, Scholz D. 2003).

FSS has a positive correlation with blood flow velocity, conversely FSS is inversely related to an increase in blood vessel diameter. An increase in blood flow velocity in preexisting collateral causes an increase in FSS. Because shear stress causes collateral growth (meaning an increase in vascular radius), FSS begins to decrease, therefore reducing the full recovery of arterial stenosis (Schaper W, Scholz D. 2003).

In addition to mechanical arteriogenesis mechanism described above, there are several chemical processes involved in the process of angiogenesis regulation. Many of these chemical mediators modulate the function of various cell types involved in the process, including the induction of cell proliferation, chemotaxis, and cell alteration (Bhamini P, et al. 2013). 


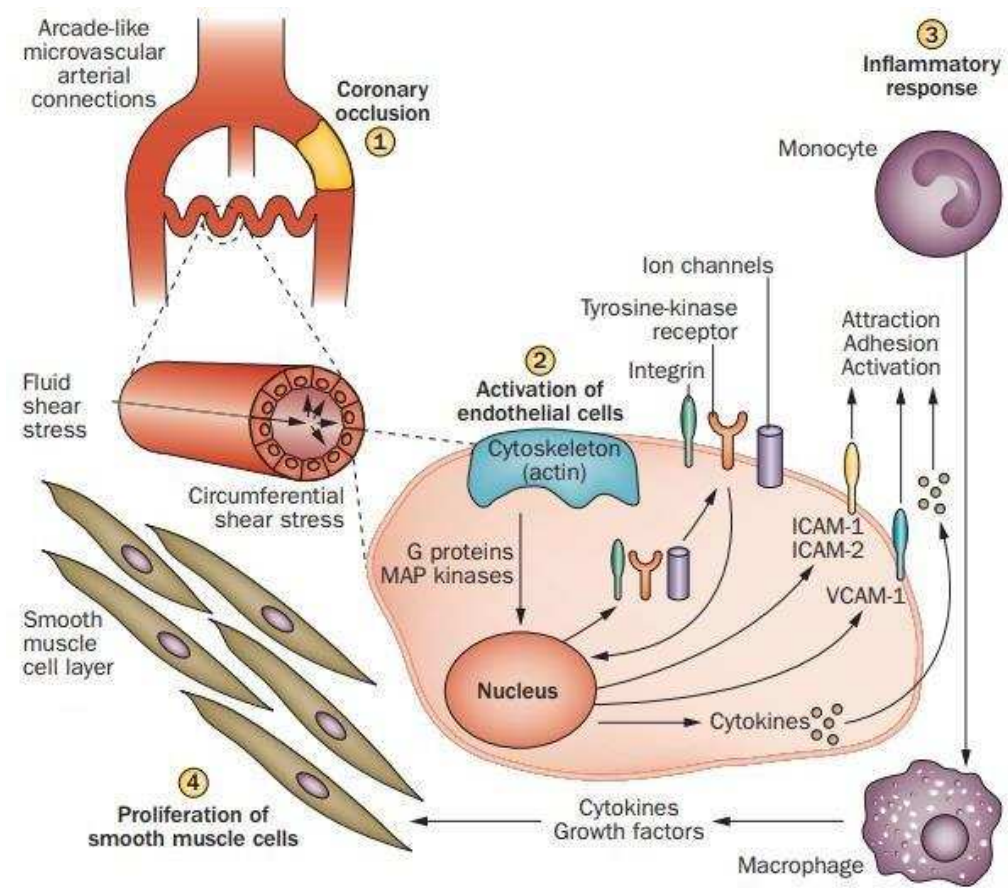

Figure 1. Arteriogenesis. In the first 24 hours after arterial occlusion (1), Shear stress activates endothelial cells (2) and causes changes in gene expression. Actin mediating the coupling between the cell membrane and the cytoskeleton acts as a sensor and, when deformed by fluid shear stress (FSS), activates a signaling cascade, including G protein and MAP kinase. This pathway induces the expression of several genes encoding chemo-attractants, activating cytokines, growth factors, and adhesion molecules, leading to monocyte migration, activation, and adhesion (3). Integrins, receptor tyrosine kinases, and ion channels in endothelial cell membranes detect, transduce, and amplify shear str ess simultaneously. Monocytes migrate through the vessel wall, transform into macrophages, and secrete cytokines and growth factors, leading to the continued formation of definitive vascular structures. Smooth muscle cells proliferate (4), and arterioles develop. Abbreviations: ICAM, intercellular adhesion molecule; MAP, mitogen-activated protein; SMC, smooth muscle cells; VCAM, vascular cell adhesion molecule (Zimarino M, et al. 2014).

\subsection{Vascular endothelial growth factor (VEGF)}

VEGF plays a major role in new blood vessel formation. Under hypoxic condition, the production and release of VEGF stimulates new capillary formation (angiogenesis) through endothelial cell sprouting, proliferation, and migration (Kofler NM, Simons M. 2015). Under different conditions, it could stimulate new artery growth, CCA formation, and changes in lumen expansion, where these events are collectively referred to as arteriogenesis (Bhanimi P, et al. 2013).

In VEGF signaling, there are three primary receptors on the cell surface that bind to it: the two tyrosine kinases receptor VEGFR-1 and VEGFR-2, and the nonkinase receptor neuropilin-1 (NRP-1) (Hollander MR, et al. 2014) (Simons M, Schwartz MA. 2012). There are several isoforms of VEGF, namely VEGF-A, that plays a role in endothelial cell function through its binding to VEGFR-2 (Kofler NM, Simons M. 2015). VEGFR-2 is also involved in signaling pathways leading to arteriogenesis through stimulation of endothelial cell proliferation, migration, and lumenization (Kofler NM, Simons M. 2015).

The first cascade begins with phosphatidylinositol 3-kinase (PI3K)/Akt activation, which inhibits apoptosis in endothelial cells and therefore promoting cell survival. This cascade is initiated by VEGF-A binding to VEGFR-2 (Flk-1), which initiates the internalization of the receptor through the plated hole in clathrin followed by 
autophosphorylation of the receptor (Kofler NM, Simons M. 2015). Active VEGFR-2 then phosphorylates PI3K, which continues to phosphorylate serine/threonine kinase Akt and will continue to target phosphorylation to inhibit apoptosis (Bhamini P, et al. 2013).

The second signaling cascade is profilin-1 phosphorylation indirectly via Src/FAK and directly via VEGFR-2, which stimulates endothelial cell migration (Kofler NM, Simons M. 2015) (Simons M, Schwartz MA. 2012). Like the previous mechanism, this cascade is initiated by VEGF-A binding to VEGFR-2. Activated VEGFR-2 then proceeds to profilin-1 phosphorylase and Src kinase, which also phosphorylates profilin-1. After phosphorylation, Profilin-1 catalyzes the exchange of ADP for ATP on G-actin, which stimulates actin polymerization and the resulting remodeling of the endothelial cell cytoskeleton. This shape changes result in the formation of actin-rich phyllopods that extend down the VEGF concentration gradient, thereby stimulating endothelial cell migration (Simons M, Schwartz MA. 2012).

The third signaling cascade is the activation of Raf-MEK-ERK signaling cascade, which stimulates endothelial cell proliferation, tissue formation, and an increase in lumen size through ERK1/2 phosphorylation (Kofler NM, Simons M. 2015). The exact mechanism of ERK1/2 on cell proliferation and motility is still not clearly defined (Bhamini P, et al. 2013). Finally, it is important to note that VEGF has been shown to be an important factor in CCA growth process (Toyota E, et al. 2005).

\subsection{Basic fibroblast growth factor (bFGF) and platelet-derived growth factor (PDGF)}

Apart from VEGF, other growth factors known to play a role in arteriogenesis are bFGF and PDGF (Bhamini P, et al. 2013). bFGF and PDGF are known to induce mitosis in endothelial and smooth muscle cells as well as exert other mitogenic effects such as promoting cell migration and differentiation (Bhamini P, et al. 2013) (Wu S, et al. 2010). bFGF stimulates this mitogenic effect through binding to the FGF receptor (FGFR) which is expressed on the cell surface (Bhamini P, et al. 2013).

Dimerized bFGF binding is useful for activating phosphorylase automatically. Activated FGFR, specifically FGFR-2 (FGFR-1 is considered a regulator of available bFGF concentration for binding to FGFR-2), then proceeds to stratified signaling by mitogen activated protein kinase (MAPK). Furthermore, it is translocated to the nucleus to initiate mitogen-promoting transcription (Bhamini P, et al. 2013). PDGF, on the other hand, is known to activate several other downstream targets including PI3K, phospholipase C (PLC), as well as MAPK to mediate their mitogenic effects (Tsioumpekou M, et al. 2016).

\subsection{Monocyte chemotactic protein 1 (MCP-1) and macrophage}

The main molecule that has been studied as part of this mechanism is monocyte chemotactic protein 1 (MCP-1) (Hollander Mr, et al. 2014). MCP-1 secretion is initiated by endothelial cell activation of MAP-kinase-protein-kinase2 (MK2) by increasing FSS pressure. Activation of MCP-1, followed by activation of monocyte's MK2, initiate migration to the correct location. In the final step of the cycle, the release of inflammatory cytokines by recruited monocytes causes an increase in MCP-1 secretion from the endothelium, resulting in further monocyte recruitment (Limbourg A, et al. 2015). 
Two adhesive molecules are particularly important to MCP-1, theye are intracellular adhesion molecule-1 (ICAM-1) and vascular cell adhesion molecule-1 (VCAM-1) which function to bind to the surface of migratory monocytes allowing them to roll along the surface of vascular lumen. Once the macrophages reach their destination, the correct phenotype must be expressed to stimulate the growth of new blood vessels. There are two main phenotypes of monocyte macrophages: M1 macrophages which secrete inflammatory molecules and help fight pathogens, and M2 macrophages which play a role in vascular growth and wound healing. These two phenotypes are induced by different cytokines, with interferon- $\gamma$ causing a shift towards the M1 phenotype, while IL-4, IL-13, and several other factors such as IL-10 and IL-33 lead to M2 differentiation. In the histological analysis of hypoxia-induced arteriogenesis, the number of M2 macrophages was shown to be increased and this suggests their important role in new vascular development (Hollander Mr, et al. 2014).

\subsection{Nitric oxide (NO) and endothelial nitric oxide synthase (eNOS)}

Nitric oxide (NO) is a potent vasodilator produced through endothelial nitric oxide synthase (eNOS) activity. eNOS has been shown to function in stimulating new vascular production, and its expression is also known to be regulated in response to increased FSS which is the main mechanical stimulus for arteriogenesis. While the exact effect of NO and eNOS on arteriogenesis is controversial, one contribution of increased NO due to increased eNOS expression is reduction of vascular endothelial cadherin (VE-cadherin), resulting in increased vascular permeability and indirect promotion of macrophage invasion (Yang B, et al. 2015). In addition, eNOS activity and pharmacological inhibition of eNOS have been shown to play a role in mediating vascular remodeling during collateral growth (Dai X, Faber JE. 2010) (Bhamini P, et al. 2013).

\subsection{Catestatin}

Catestatin is a neuroendocrine peptide derived from a specific cleavage of large protein from human chromogranin A (CgA) (Bhamini P, et al. 2013). It functions in many different processes in the body, including histamine secretion from mast cells, defense against microbes, vasodilation, and monocyte attraction. It has also been observed that catestatin acts in a pro-angiogenic capacity, being involved in inducing endothelial cell proliferation and migration as well as capillary tube formation. This is achieved through the stimulation of bFGF release, which in turn activates MAPK via binding to FGFR-1 as previously discussed (Xu W, et al. 2016) (Theurl M, et al. 2010).

It has also been shown that catestatins activate other signaling cascades such as PI3K/Akt, serving an antiapoptotic role to promote cell survival. Finally, catestatin affects effects on endothelial progenitor cells (EPC) and vascular smooth muscle cells (VSMC) in addition to direct effects on endothelial cells. It also induces chemotaxis to incorporate these cell types into the formation of new vasculature (Theurl, et al. 2010).

\subsection{Neuregulins (NRG)}

Neuregulins are another class of molecules produced by endothelial cells. This growth factor ligand binds to the erbB receptor which is expressed on the endothelial cell surface. This action has been shown to induce angiogenesis 
(Hedhli N, et al. 2012). The involvement of NRGs in angiogenesis and arteriogenesis is related to the regulation of $\alpha \mathrm{v} \beta 3$ integrin, thereby playing a role in cell migration, proliferation, and differentiation mechanisms. The mechanism by which this occurs involves another proangiogenic protein, Cyr61, where its expression is regulated by NRG-erbB signaling in addition to mediation through VEGF release induction and subsequent activation of ERK signaling cascade. ErbB receptors have also been found to be expressed on EPCs, playing a role in enhancing cell survival and in certain types of VSMCs. (Hedhli N, et al. 2012)

\subsection{Early growth response-1 (Egr-1)}

Early growth response 1 (Egr-1) is a transcription factor from the zinc-finger family that has been shown to be regulated during arteriogenesis. This Egr-1 plays a major role in modulating the level of other growth factors involved in the collateral growth process, including playing a role in the formation and proliferation of leukocytes (Pagel JI, et al. 2012) (Sarateanu CS, et al. 2006). Specific genes regulated by Egr-1 include PDGF and transforming growth factor- $\beta$ (TGF- $\beta$ ), which then indirectly increase other factors involved in collateral growth such as VEGF and matrix metalloproteinases (MMP) in angiogenesis such as MMP- 1, MMP-8, and MMP-13 (Sarateanu CS, et al. 2006).

Interestingly, despite the fact that most of these factors were shown to influence angiogenesis, it has been observed that Egr-1 mainly affects the growth of arterioles rather than capillaries, suggesting its major role in the regulation of arteriogenesis (Sarateanu CS, et al. 2006). As with other factors, the production of Egr-1 is stimulated mainly by increased FSS, in this case by activating the Egr-1 gene promoter. It has been suggested that this is mediated by the Ras-MEK-ERK1/2 signaling cascade in which shear stress leads to MEK1 activation, which continues to activate ERK1/2 of the MAPK family, and finally ERK1/2 activates the Elk-1 protein that induces Egr1 transcription. Furthermore, this pathway could be activated by a very low increase in shear stress due to ERK1/2 sensitivity (Bhamini P, et al. 2013).

\section{CCA classification and assessment}

Anatomically, CCA could be divided into epicardial and intramyocardial CCA. Both types of CCA, whether it is the thin-walled intramyocardial microcollateral vessels without the tunica media or the larger epicardial collateral vessels that have tunica media, develop in advanced atherosclerotic disease. Despite the clinical importance of CCA, identification of collateral circulation is limited due to the insensitivity of currently available techniques. One of the available techniques is conventional angiography which is only able to identify blood vessels that are more than 180 micrometers in diameter. It limits detection to a few epicardial collateral vessels and will not be able to detect smaller intramyocardial vessels (Pearlman JD et al, 2000).

Several methods could be used to evaluate CCA (Berry C, et al. 2007). Visual CCA assessment using coronary angiography is the most convenient technique. The assessment uses the Rentrop score (Seiler C. 2009). This visual method has several other limitations, including not being objective, influenced by blood pressure, the strength of contrast injection, and the duration of visual collection.

Semi-quantitative CCA assessment in patients with Choronic Total Occlution (CTO) refers to a physiological measurement of collateral function using the collateral connection assessment method $(\mathrm{CC}$ grade $0=$ no continuous 
connection between collateral donor and recipient; $\mathrm{CC} 1=$ thin thread-like continuous connection appears; $\mathrm{CC} 2=$ connection appears similar to a side branch) (Werner GS. et al. 2003). This assessment is also the basis for assessing potential collateral access in planning coronary intervention for CTO using a retrograde recanalization approach (Werner G. 2014).

Flow velocity is measured with a Doppler sensor distal to the vessel occlusion area originating from the CCA. Angioplasty is then performed on the vessels and the flow velocity is measured again, which represents the flow through the normal vessels. The velocity of collateral flow is compared with the velocity of flow through an open coronary artery and indicates the percentage of normal blood flow that could be maintained through the collateral circulation in the event of sudden vessel occlusion (Seiler C. 2010).

To understand further, refer to the illustration in Figure 2A. Evaluation using CFI pressure measurement can be calculated by the formula:

$$
\mathrm{CFI}_{\mathrm{p}}=\left(\mathrm{P}_{\text {occl }}-\mathrm{CVP}\right) /\left(\mathrm{P}_{\mathrm{ao}}-\mathrm{CVP}\right)
$$

Where CFIp is the CFI pressure, Poccl is the intracoronary occlusive pressure, Pao is the aortic pressure, and CVP is the central venous pressure (Möbius-Winkler S, et al. 2016; Wustmann K, et al. 2003). Although this index has untested assumptions, it is an acceptable estimate of collateral growth.

A simpler, cheaper and reliable method for measuring CCA function is the electrocardiogram (ECG) (de Marchi, et al. 2012). Its assessment is through evaluation of the ST segment 1-2 minutes during vessel occlusion using balloon angioplasty. If during vessel occlusion the patient experiences chest pain and ST segment elevation $\geq 0.1 \mathrm{mV}$, it is considered as a sign of inadequate collateral function. The three methods above, Rentrop score, CFI and ECG evaluation on intracroronary artificial occlusion could predict clinical outcome (Meier P, et al. 2012). Other method includes 'wash-out collaterometry', where the distal contrast clearance time is assessed during arterial occlusion using balloon angioplasty. Faster contrast clearance indicates good collateral function (Seiler, et al. 2001).
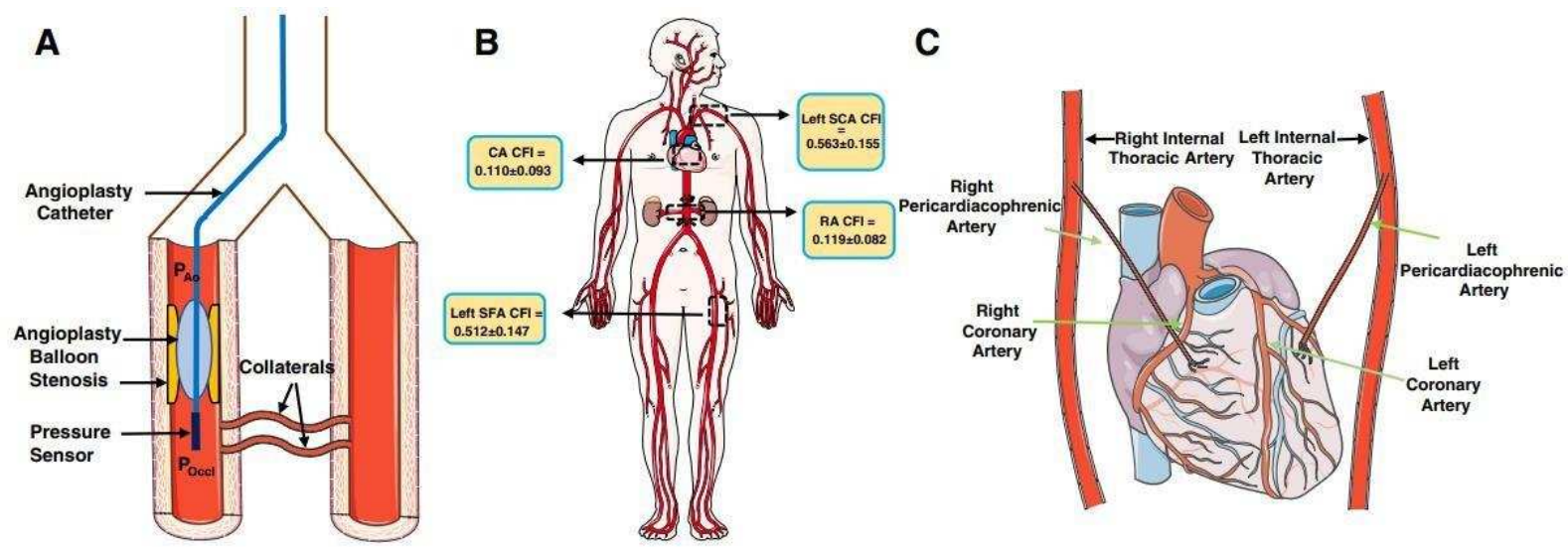

Figure 2. Clinical aspects of CCA. A: A schematic showing the calculation of the collateral flow index (CFI). Pao, aortic pressure; Poccl, distal intracoronary occlusive pressure. CFI could be calculated by the formula: $\left(\mathrm{P}_{\mathrm{occl}}-\mathrm{CVP}\right) /\left(\mathrm{P}_{\mathrm{a}}-\mathrm{CVP}\right)$, where $\mathrm{CVP}$ is the central venous pressure. B: CFI as calculated by Stoller et al. in different systemic arterial regions. CA, coronary arteries; left SCA, left subclavian artery; RA, renal arteries; left SFA, left superficial femoral artery. C: schematic showing right and left internal thoracic (mammary) orientation with respect to the heart. The internal thoracic arteries become the pericardiophrenic arteries, which supply blood to the heart. Stoller and Seiler (Stoller M, Seiler C. 2016) reported increased CFI (in RCA) in patients whose distal right internal thoracic arteries had permanently closed. (Jamaiyar, et al. 2019)

\section{CCA functional relevance}




\subsection{Beneficial Effects of CCA}

It has been recognized that a properly functioning collateral supply could reduce ischemia and infarction area, maintain ventricular function, prevent ventricular remodeling, and aneurysm formation. There is evidence that the presence of extensive CCA has a good prognosis for patient survival (Seiler C, Meier P. 2014).

In general, the beneficial effect of well-functioning collateral is related to myocardial salvage. A patient with good collateral flow and salvagable myocardium was reported, as demonstrated by a normal ejection fraction (EF) despite more than one coronary artery occlusion. Cases of proximal coronary occlusion in elderly patients. The patient had normal EF values despite total proximal occlusion of the three major coronary arteries (Fig. 3). With these results, it dould be concluded that the supply of collateral during occlusion is sufficient to save the myocardium (Seiler C, Meier P. 2014).

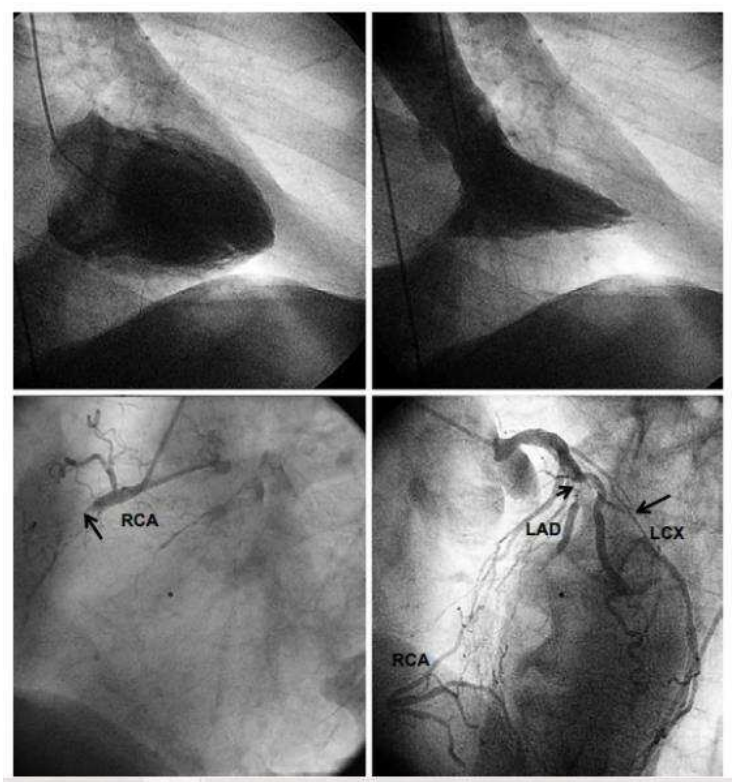

Figure 3. Normal left ventricular angiogram (upper panel) in a patient with chronic proximal occlusion of all three major coronary arteries (lower panel) provides evidence for a myocardial salvage effect on CCA. The only vessel that is not occluded is the intermediate bra nch. RCA: right coronary artery; LAD: left anterior descending coronary artery: LCX; left circumflex coronary artery (Seiler C, Meier P. 2014).

Another case (figure 4) of a 72-year-old male patient with grade III collaterals on the anterior wall of the LV with proximal left anterior descending (LAD) occlusion. The single atrial collateral artery originating from the ostium of right coronary artery (RCA) supplies sufficient flow to completely replace the LAD area at risk of infarction. The more proximal collateral vessels originating from the RCA compete with the main collateral vessels, because of the “competitive filling” originating from the proximal septal collateral artery (Seiler C, Meier P. 2014). 

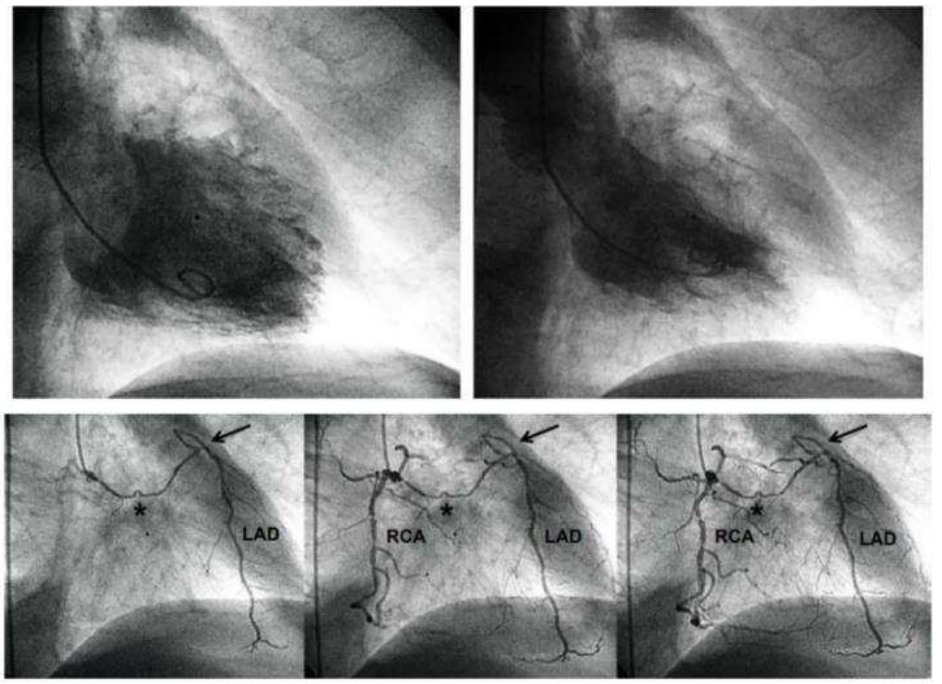

Figure 4. Normal left ventricular angiogram (upper panel) in a patient with chronic occlusion of the proximal left anterior descending (LAD; lower panel, cranial, anterior and posterior views). Contrast injection into the RCA with the first image showing conus branches of the collateral arteries to the LAD $(*)$. Second, the atrial collateral artery between the RCA and the LAD (middle and right lower panels) is filled with contrast from the two coronary arteries, thus depicting the competing collateral flow between the RCA and LAD (Seiler C, Meier P. 2014)..

Another example of collateral beneficial effect is illustrated in Figure 5. A 55-year-old female patient was admitted for an invasive cardiac examination in the context of atypical chest pain. Despite the normalization of LV systolic function, the absence of exercise-induced angina pectoris suggested another beneficial effect of very large distal epicardial branch of collateral artery from the RCA to the LAD (Seiler C, Meier P. 2014).

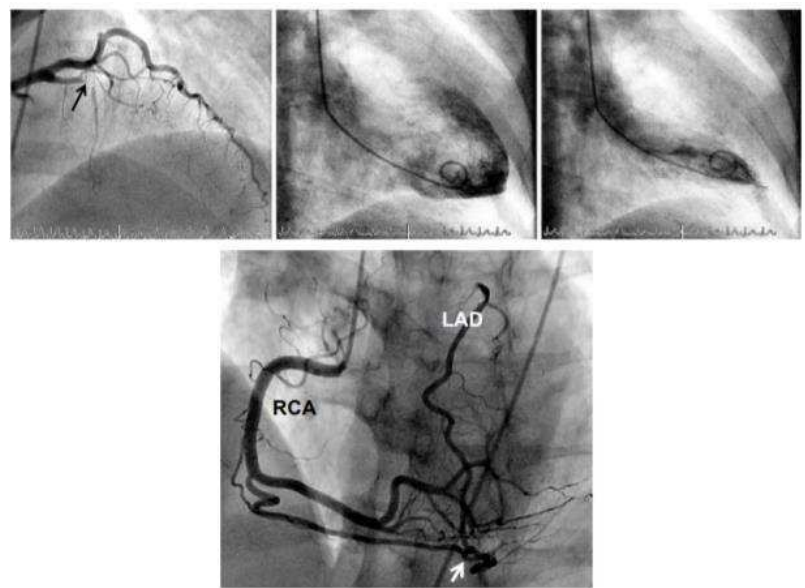

Figure 5. Coronary angiogram (view from left anterior oblique cranial; left panel) with chronic occlusion of LAD in the first diagonal and septal branches and normal left ventricular angiogram (middle and left panels) showcases another case of myocardial function salvage with welldeveloped collaterals. Bottom panel: Coronary angiogram (slight left anterior oblique cranial view) with contrast injection into the right coronary artery (RCA) and complete filling of isolated LAD via large branch collateral artery.

\section{CCA PROGNOSTIC SIGNIFICANCE}

In order to estimate the true protective effect of collateral, it is necessary to adjust several indicators such as the degree of stenosis, the number of vessels involved, the initial revascularization strategy chosen, and the history of 
MI. From a clinical perspective and patient prognosis, the overall benefit of collateral could not be separated from the severity of the underlying disease (Steg PG, et al. 2011).

However, a study conducted by Seiler C in 2003 found that the protective ability of collateral provides a similar risk estimate across ischemic heart disease burden strata (Seiler C. 2003). Therefore, in a broad spectrum of CAD, the protective effect of collateral does not appear to be dependent on CAD severity. These findings hold promise for collateral activation by growth factors and cell therapy for angio-, vasculo-, and arteriogenesis, aimed at patients with extensive coronary artery disease who suffer from refractory angina (Steg PG, et al. 2011).

\subsection{Coronary collateral artery $(\mathrm{CCA})$ in stabile $\mathrm{CAD}$}

Collateral coronary arteries are present in about $30 \%$ of patients with stable CAD. CCA flow has been shown to play an important role in correlation with angina severity. A 10-year follow-up angiographic study showed collateral growth was correlated with reduced angina. Collateral flow capacity was increased more than threefold in patients with enhanced angina, whereas collateral flow remained constant in subjects without increased angina (Rockstroh J, Brown BG. 2002). Pijls et al revealed that physiologically recruitable collateral has an accurate value in predicting ischemia occurrence in ECG during balloon inflation (area under the receiver operating curve 0.97) (Pijls NH, et al. 1995).

Spontaneous collateral angiographic assessment is limited by wide inter-observer variation. Currently, CFI measurement is considered the method of choice for determining functional collateral flow. The CFI cut-off at 0.25 has a significant discriminatory value in predicting ischemia. In a study of 403 patients with stable CAD, the occurrence of ST segment changes during balloon occlusion was significantly lower in the group with CFI 0.25 than in the group with CFI $<0.25$ (25\% vs. 86\%) (Billinger M, et al. al. 2002).

Formed (physiologically measured) and spontaneous collaterals have both been shown to have prognostic benefits to future cardiac chemical events. Regieli et al have shown that $92 \%$ of patients with spontaneous collaterals (angiography) compared with $84 \%$ of patients without collateral survived myocardial infarction (MI), cardiac death, and unscheduled revascularization (Regieli, et al. 2009).

The protective effect provided by collateral appears to vary significantly across groups with different levels of coronary disease. Meier et al revealed that sufficiently recruitable collateral flow (CFI >0.25) saved lives in patients with chronic stable CAD (Meier P, et al. 2007). Depending on the amount of collateral flow that can be recruited during a brief coronary occlusion, long-term cardiac death was reduced by $1 / 4$ compared to patients without collateral supply. Mortality in the presence of well-developed collaterals continued to decrease beyond the 5-year follow-up, which could be explained by the importance of "natural bypass" CCA during the increasing progression of CAD (Meier P, et al. 2007).

\subsection{Coronary collateral artery (CCA) in Myocardial Infarct}

Collateral vessels have been shown to be easily recruited during acute balloon occlusion. In humans with normal coronary arteries, $1 / 5$ and up to $1 / 4$ patients have easily recruitable collaterals with CFI $\geq 0.25$ and almost all of these show no signs of myocardial ischemia during balloon occlusion (Wustmann K, et al. 2003). This shows that a 
proportion of patients might have collaterals that are easily expandable during acute coronary occlusion in myocardial infarction event. In patients with acute myocardial infarction within 12 hours ( $\mathrm{n}=248), 37 \%$ had collateral during angiography (Hollander MR, et al. 2014). In another group of patients with STEMI within $<6$ hours ( $\mathrm{n}=1059)$, the prevalence of Rentrop grade 1 and 2-3 collaterals was 36\% and 10\%, respectively (Elsman P, et al. 2004).

Meisel et al found a CFI of $0.35 \pm 0.13$ (range 0.11 - 0.7) in patients with Acute Myocardial Infarction (AMI) within 24 hours (Meisel SR, et al. 2010). Interestingly, CFI in AMI shows a Gaussian distribution similar to results that were observed by Pohl et al in chronic CAD, but with a higher proportion (70\%) of patients having CFI >0.25 (Pohl T, et al. 2001). These findings suggest that in AMI, the pressure is measured after several hours of occlusion, a much longer period than for the selected patient (only a few minutes of balloon occlusion). The presence of collaterals during AMI raises the question of whether this presence actually plays a beneficial role in terms of limiting infarct size, preserving ventricular function, limiting infarct complications, and ultimately improving the prognosis of AMI patients. A number of studies have addressed this issue and most have given positive results. Elsman et al revealed that the presence of angiographically visible collaterals, especially with Rentrop class 2-3 during AMI, has a protective effect on enzymatic infarct size and on hemodynamic conditions before and after revascularization (Elsman P, et al. 2004).

This beneficial effect is particularly evident in LAD infarcts. These findings support the hypothesis that the presence of collateral flow in the first hours after acute coronary occlusion plays an important role in maintaining the compromised myocardium until reperfusion is achieved. The findings by Habib et al support the notion that the presence of collateral during AMI is associated with infarct size limitation and ventricular function improvement (Habib GB, et al. 1991).

Yoon SJ et al studied 125 patients who failed thrombolysis. They observed a similar effect for anterior and nonanterior infarct locations. Infarct size was assessed by cardiac magnetic resonance imaging (Yoon SJ, et al. 2009). Using coronary-injected myocardial contrast echocardiography, Sabia et al analyzed the correlation between myocardial viability and collateral blood flow in 43 patients with recent myocardial infarction (mean=12 days post MI) (Sabia PJ, et al. 1992). With advanced technique, they demonstrated that the presence of myocardial collateral flow in the unused bed remains potentially viable for long periods of time. Patients with good collateral flow have significantly better ventricular wall motion after angioplasty than those with poor collateral flow (Sabia PJ, et al. 1992).

Regarding the role of collateral in MI complications, several studies have yielded positive results. Hirai et al documented the role of collateral in limiting left ventricular aneurysm formation after AMI (58\% and 10\% for poor and good collateral flow, respectively) ( $\mathrm{Ng} \mathrm{S.} \mathrm{2012).} \mathrm{This} \mathrm{could} \mathrm{be} \mathrm{explained,} \mathrm{at} \mathrm{least} \mathrm{in} \mathrm{part,} \mathrm{by} \mathrm{the} \mathrm{fact} \mathrm{that} \mathrm{well-}$ developed collateral flow maintains a decent amount of myocardium in the center of the infarcted area, thereby strengthening its tensile strength and preventing aneurysm formation.

Pretre R et al. have evaluated the frequency of collateral blood flow in infarcted coronary arteries with ventricular septal defects after AMI $(n=33)$. The main finding of their study was that post-MI ventricular septal defects occur in a highly susceptible myocardium that is suddenly made ischemic by occlusion of the myocardium unprotected by collateral blood flow and unprepared by ischemic preconditioning (Pretre R, et al. 2000). 
Pérez-Castellano et al found higher in-hospital mortality in patients with anterior MI and without collateral despite treatment with angioplasty within 6 hours of onset (23\% in patients without collateral and $8 \%$ in guarantee). This beneficial effect is contributed by the protection of complications from cardiogenic shock (26\% and malignant arrhythmias (21\% vs. 9\%). The role of collateral in limiting infarct size appears to account for its life-saving benefit (Garci EJ, et al. 1998).

Arrhythmia as one of the causes of sudden death due to coronary occlusion could be prevented by the presence of collateral. Alleviation of acute myocardial ischemia by collateral circulation during sudden vessel occlusion might prevent electrical instability. Meier et al have shown evidence that collateral circulation prevents QT prolongation during brief coronary occlusion, suggesting a protective mechanism against myocardial electrical instability (Meier P, et al. 2010).

Gohlke et al found that the presence of collateral (during angiography within one year) after anterior Q wave MI was associated with more severe left ventricular dysfunction and more cardiac events at an 8-year follow-up. Their data also showed that collateral was associated with more severe coronary stenosis. With careful interpretation, the presence of collaterals found after MI could only reflect disease severity (lower ejection fraction and more severe stenotic or antegrade flow), which in turn are major adverse factors for prognosis (Gohlke H, et al. al. 1991).

Investigators from the Occluded Artery Trial (OAT) analyzed the effect of collateral flow to the infarcted arterial area on long-term clinical outcomes including mortality, reinfarction, and hospitalization for class IV heart failure. They found that the 60-month cumulative incidence rate was higher in those without collateral than in those with collateral $(22.7 \%$ and $16.9 \%$, respectively). This main outcome was largely due to the higher incidence of mortality and heart failure events (Steg PG, et al. 2011).

\subsection{Prognostic impact and function of CCA in $\mathrm{CAD}$ patients}

CCA presence could prevent myocardial ischemia in both healthy and CAD subjects. CCA circulation might lead to reduced ischemia, maintenance of ventricular function, and improved prognosis (Seiler C. 2010). In chronic progressive $\mathrm{CAD}$, the CCA develops vigorously and in some cases might provide sufficient flow to maintain myocardial perfusion and protect the heart from future adverse events. Twenty-five to thirty percent of CTO patients with CCA Rentrop value of 2 or 3 mighy maintain functional myocardial perfusion.

In cases of acute myocardial infarction, the benefit of collateral might be questionable because of acute coronary occlusion occurrence. It is known that functional collateral recruitment takes considerable time to be effective. Collateral recruitment is a dynamic process of vascular remodeling. Generally, it takes 3 to 5 days after coronary occlusion before there is measurable collateral. Interestingly, however, $\mathrm{Ng} \mathrm{S}$ et al's studies have found that a substantial percentage ( $10 \%$ to $20 \%$ ) of individuals develop collaterals in acute myocardial infarction and this is confirmed also by Elsman P et al's (Ng S, et al. 2012) studies (Elsman P et al. 2012) (Elsman P, et al. 2004).

There is some evidence that collateral is associated with a reduced risk of left ventricular aneurysm, rupture, cardiogenic shock and fatal arrhythmias during acute myocardial infarction. Collateral might prevent adverse events that occur by reducing the number of unused myocardial cells. It is important to understand that collateral might be 
beneficial in myocardial infarction patients. Studies from Habib et al and Elsman et al reported evidence of the importance of collateral in humans (Habib GB, et al. 1991) (Elsman P, et al. 2004).

A study conducted by $\mathrm{Ng} \mathrm{S}$ et al confirmed that there is a significant correlation between the presence of collateral and reduced infarct size. When acute coronary occlusion occurs, the initial phase of myocardial infarction begins. Infarct size increases as ischemia persists. The ideal scenario is that as soon as an acute coronary occlusion occurs, an alternative pathway is immediately available, avoiding fatal damage to the myocardium (Figure 3). When area at risk area reduces, the infarct size will be smaller, and hemodynamic and fatal arrhythmic complications that occur after myocardial infarction could also be avoided. Moreover, successful acute revascularization could still be achieved after unavoidable logistical delays if more area could be saved and maintained through collateral flow presence (Ng S, et al. 2012).

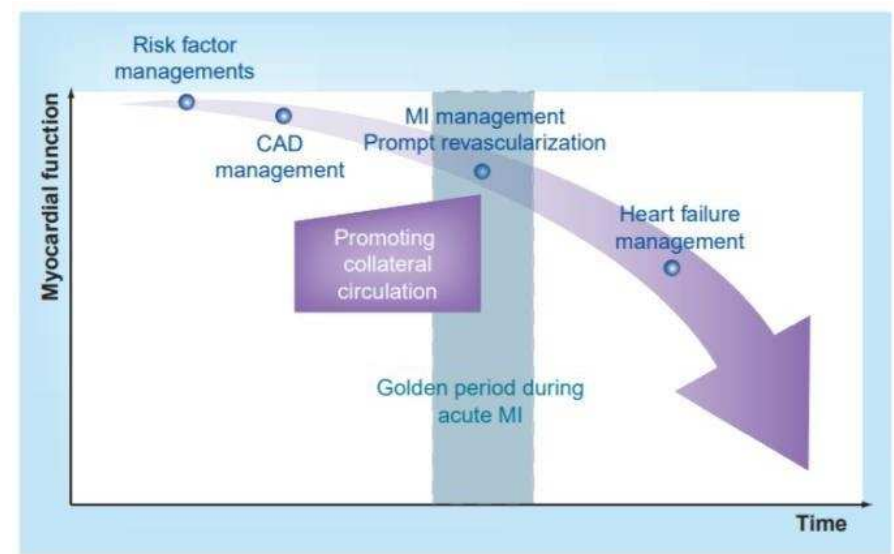

Figure 3. The ideal concept of collateral relevance in the management steps of myocardial infarction (Ng S, et al. 2012)..

\section{Conclusion}

Well-developed CCA circulation is associated with reduced infarct size, LV dysfunction, and all-cause mortality in patients with CAD. Furthermore, accurate and quantitative assessment is needed to differentiate patients with adequate or inadequate collateral function to prevent ischemia during coronary occlusion. Currently, the gold standard in determining it is still an invasive method with CFI measurement using pressure assessment.

\section{Acknowledgements}

The authors would like to thank the head of department and the study program coordinator of Cardiology and Vascular Medicine, Airlangga University Faculty of Medicine, Surabaya, Indonesia.

\section{References}

Berry C, Balachandran KP, L'Allier PL, Lespérance J, Bonan R, Oldroyd KG. Importance of collateral circulation in coronary heart disease. Eur Heart J. 2007;28(3):278-91.

Bhamini P, Peter Hopmann MD, Kanithra Sekaran, Kathleen Graham LY and, Chilian W. Coronary Collateral Growth: Clinical Perspectives and Recent Insights. Intech. 2013;32(7):137-44. 
Billinger M, Kloos P, Eberli FR, Windecker S, Meier B, Seiler C. Cardiac Catheterization and Intervention Physiologically Assessed Coronary Collateral Flow and Adverse Cardiac Ischemic Events : A Follow-Up Study in 403 Patients With Coronary Artery Disease. J Am Coll Cardiol. 2002;40(9):1545-50.

Dai X, Faber JE. Endothelial nitric oxide synthase deficiency causes collateral vessel rarefaction and impairs activation of a cell cycle gene network during arteriogenesis. Circ Res. 2010;106(12):1870-1881.

de Marchi SF, Streuli S, Haefeli P, Gloekler S, Traupe T, Warncke C, Rimoldi SF, Stortecky S, Steck H, Seiler C: Determinants of prognostically relevant intracoronary electrocardiogram st-segment shift during coronary balloon occlusion. Am J Cardiol. 2012;110:1234-1239. https://doi.org/10.1016/j.amjcard.2012.06.023

Elsman P, Van't Hof AWJ, De Boer MJ, Hoorntje JCA, Suryapranata H, Dambrink JHE, et al. Role of collateral circulation in the acute phase of ST-segment-elevation myocardial infarction treated with primary coronary intervention. Eur Heart J. 2004;25(10):854-8.

Fujita M, Tambara K. Recent insights into human coronary collateral development. Heart. 2004;90(3):246-250.

Garci EJ, Serrano A, Eli J, Soriano J, Lo L. Influence of Collateral Circulation on In-Hospital Death From Anterior Acute Myocardial Infarction. 1998;31(3):512-8.

Gohlke H, Heim E, Roskamm H. Prognostic importance of collateral flow and residual coronary stenosis of the myocardial infarct artery after anterior wall Q-wave acute myocardial infarction. Am J Cardiol. 1991;67(15):1165-9.

Habib GB, Heibig J, Forman SA, Brown BG, Roberts R, Terrin ML, et al. Influence of coronary collateral vessels on myocardial infarct size in humans. Results of Phase I thrombolysis in myocardial infarction (TIMI) trial. Circulation. 1991;83(3):739-46.

Hedhli N, Dobrucki LW, Kalinowski A, Zhuang ZW, Wu X, Russell RR, 3rd, et al. Endothelial-derived neuregulin is an important mediator of ischaemia-induced angiogenesis and arteriogenesis. Cardiovasc Res. 2012;93(3):516-524.

Hirai T, Fujita M, Yamanishi K, Ohno A, Miwa K, Sasayama S: Significance of preinfarction angina for preservation of left ventricular function in acute myocardial infarction. Am Heart J. 1992;124:19-24.

Hollander MR, Horrevoets AJ, van Royen N. Cellular and pharmacological targets to induce coronary arteriogenesis. Curr Cardiol Rev. 2014;10(1):29-37.

Jamaiyar A, Juguilon C, Dong F, Cumpston D, Enrick M, Chilian WM, et al. Cardioprotection during ischemia by coronary collateral growth. AmJ Physiol - Hear Circ Physiol. 2019;316(Berry, C. et al. 2007):1-9.

Kofler NM, Simons M. Angiogenesis versus arteriogenesis: neuropilin 1 modulation of VEGF signaling. $2015 ; 7: 26$.

Limbourg A, von Felden J, Jagavelu K, Krishnasamy K, Napp LC, Kapopara PR, et al. MAP-kinase activated protein kinase 2 links endothelial activation and monocyte/macrophage recruitment in arteriogenesis. PLoS One. 2015;10(10):e0138542.

Meier P, Gloekler S, Zbinden R, Beckh S, De Marchi SF, Zbinden S, et al. Beneficial effect of recruitable collaterals: A 10-year follow-up study in patients with stable coronary artery disease undergoing quantitative collateral measurements. Circulation. 2007;116(9):975-83.

Meier P, Gloekler S, de Marchi SF, Zbinden R, Delacretaz E, Seiler C. An indicator of sudden cardiac death during brief coronary occlusion: electrocardiogram QT time and the role of collaterals. Eur Heart J. 2010; 31(10):1197-204. 
Meier P, Hemingway H, Lansky AJ, Knapp G, Pitt B, Seiler C. The impact of the coronary collateral circulation on mortality: a meta-analysis. Eur Heart J. 2012;33:614-621.

Meier P, Indermuehle A, Pitt B, Traupe T, Marchi SF De, Crake T, et al. Coronary collaterals and risk for restenosis after percutaneous coronary interventions : a meta-analysis. BMC Med [Internet]. 2012;10(1):62.

Meier P, Schirmer SH, Lansky AJ, Timmis A, Pitt B, Seiler C. The collateral circulation of the heart. BMC Med. 2013;11(1):1.

Meisel SR, Shochat M, Frimerman A, Asif A, Blondheim DS, Shani J, et al. Collateral pressure and flow in acute myocardial infarction with total coronary occlusion correlate with angiographic collateral grade and creatine kinase levels. Am Heart J [Internet]. 2010;159(5):764-71. Available from: https://doi.org/10.1016/j.ahj.2010.02.011

Möbius-Winkler S, Uhlemann M, Adams V, Sandri M, Erbs S, Lenk K, et al. Coronary Collateral Growth Induced by Physical Exercise: Results of the Impact of Intensive Exercise Training on Coronary Collateral Circulation in Patients with Stable Coronary Artery Disease (EXCITE) Trial. Circulation. 2016;133(15):1438-48.

Ng S. Coronary collaterals: occurence and functions. Dissertation Utr Univ. 2012;

$\mathrm{Ng} \mathrm{S}$, Soerianata S, Andriantoro H, Ottervanger JP, Grobbee DE. Timing of coronary collateral appearance during ST-elevation myocardial infarction. Interv Cardiol. 2012;4(1):137-43.

Pagel JI, Ziegelhoeffer T, Heil M, Fischer S, Fernandez B, Schaper W, et al. Role of early growth response 1 in arteriogenesis: impact on vascular cell proliferation and leukocyte recruitment in vivo. Thromb Haemost. 2012;107(3):562-574. Coronary Collateral Growth: Clinical Perspectives and Recent Insights

Pearlman JD, Laham RJ, Simons M. Coronary angiogenesis: detection in vivo with mr imaging sensitive to neocirculation—-preliminary study in pigs. Radiology 2000; 214:801-807.

Pijls NHJ, Willem Bech GJ, El Gamal MIH, Bonnier HJRM, De Bruyne B, Van Gelder B, et al. Quantification of recruitable coronary collateral blood flow in conscious humans and its potential to predict future ischemic events. J Am Coll Cardiol. 1995;25(7):1522-8.

Pohl T, Seiler C, Billinger M, Herren E, Wustmann K, Mehta H, et al. Frequency Distribution of Collateral Flow and Factors Influencing Collateral Channel Development Functional Collateral Channel Measurement in 450 Patients With Coronary Artery Disease. J Am Coll Cardiol [Internet]. 2001;38(7):1872-8.

Pretre R, Rickli H, Ye Q, Benedikt P, Turina MI. Frequency of collateral blood flow in the infarctrelated coronary artery in rupture of the ventricular septum after acute myocardial infarction. Am J Cardiol. 2000;85(8):4979.

Regieli JJ, Jukema JW, Nathoe HM, Zwinderman AH, Ng S, Grobbee DE, et al. Coronary collaterals improve prognosis in patients with ischemic heart disease. Int J Cardiol [Internet]. 2009;132(2):257-62. Available from: http://dx.doi.org/10.1016/j.ijcard.2007.11.100

Sabia PJ, Powers ER, Ragosta M, Sarembock IJ, Burwell LR, Kaul S. An association between collateral blood flow and myocardial viability in patients with recent myocardial infarction. N Engl J Med. 1992;327(12):1825-1.

Sarateanu CS, Retuerto MA, Beckmann JT, McGregor L, Carbray J, Patejunas G, et al. An Egr-1 master switch for arteriogenesis: studies in Egr-1 homozygous negative and wild type animals. J Thorac Cardiovasc Surg. 2006;131(1):138-145.

Schaper W, Scholz D. Factors regulating arteriogenesis. Arterioscler Thromb Vasc Biol. 2003;23(7):1143-1151. 
Seiler C, Fleisch M, Meier B. Direct intracoronary evidence of collateral steal in humans. Circulation. 1997;96(12):4261-7.

Seiler C, Fleisch M, Garachemani A, Meier B. Coronary collateral quantitation in patients with coronary artery disease using intravascular flow velocity or pressure measurements. J Am Coll Cardiol [Internet]. 1998;32(5):1272-9.

Seiler C, Billinger M, Fleisch M, Meier B. Washout collaterometry: a new method of assessing collaterals using angiographic contrast clearance during coronary occlusion. Heart. 2001;86:540-546.

Seiler C. Collateral Circulation of the Heart. London, UK: Springer-Verlag; 2009.

Seiler C. The human coronary collateral circulation. Eur J Clin Invest. 2010;40:465-476.

Seiler C, Engler R, Berner L, Stoller M, Meier P, Steck H, et al. Prognostic relevance of coronary collateral function: Confounded or causal relationship? Heart. 2013;99(19):1408-14.

Seiler C, Meier P. Historical Aspects and Relevance of the Human Coronary Collateral Circulation. Curr Cardiol Rev. 2014;10(1):2-16.

Simons M, Schwartz MA. Profilin phosphorylation as a VEGFR effector in angiogenesis. Nat Cell Biol. 2012;14(10):985-987.

Smith RD, Ilsley CD. Clinical contribution of the collateral circulation to myocardial protection. Coron Artery Dis. 2004; 15:393-8.

Steg PG, Kerner A, Mancini GB, Reynolds HR, Carvalho AC, Fridrich V, et al. Impact of collateral flow to the occluded infarct-related artery on clinical outcomes in patients with recent myocardial infarction: a report from the randomized Occluded Artery Trial. NIH Public Access. 2011;121(25):2724-30.

Stoller M, Seiler C. Intraindividual variability and association of human collateral suplaito different arterial regions. Am J Cardiol. 2016;117: 685-690.

Theurl M, Schgoer W, Albrecht K, Jeschke J, Egger M, Beer AG, et al. The neuropeptide catestatin acts as a novel angiogenic cytokine via a basic fibroblast growth factor-dependent mechanism. Circ Res. 2010;107(11):1326-1335.

Toyota E, Warltier DC, Brock T, Ritman E, Kolz C, O'Malley P, et al. Vascular endothelial growth factor is required for coronary collateral growth in the rat. Circulation. 2005;112(14):2108-2113.

Tsioumpekou M, Papadopoulos N, Burovic F, Heldin CH, Lennartsson J. Platelet-derived growth factor (PDGF)induced activation of Erk5 MAP-kinase is dependent on Mekk2, Mek1/2, PKC and PI3-kinase, and affects BMP signaling. Cell Signal. 2016;28(9):1422-1431.

Van Royen N, Piek JJ, Buschmann I, Hoefer I, Voskuil M, Schaper W. Stimulation of arteriogenesis; a new concept for the treatment of arterial occlusive disease. Cardiovasc Res. 2001;49(3):543-553.

Wani S, Seiler C. Images in cardiovascular medicine Transcoronary ablation of septal hypertrophy in HOCM: septal collaterals may cause unwanted inferior myocardial infarction. 2007;401-2.

Werner G. The Role of Coronary Collaterals in Chronic Total Occlusions. Curr Cardiol Rev. 2014;10(1):57-64.

Werner GS, Ferrari M, Heinke S, Kuethe F, Surber R, Richartz BM, Figulla HR. Angiographic assessment of collateral connections in comparison with invasively determined collateral function in chronic coronary occlusions. Circulation. 2003;107:1972-7. 
Wu S, Wu X, Zhu W, Cai WJ, Schaper J, Schaper W. Immunohistochemical study of the growth factors, aFGF, bFGF, PDGF-AB, VEGF-A and its receptor (Flk-1) during arteriogenesis. Mol Cell Biochem. 2010;343(12):223-229.

Wustmann K, Zbinden S, Windecker S, Meier B, Seiler C. Is there functional collateral flow during vascular occlusion in angiographically normal coronary arteries? Circulation. 2003;107(17):2213-20.

Xu W, Yu H, Li W, Gao W, Guo L, Wang G. Plasma catestatin: a useful biomarker for coronary collateral development with chronic myocardial ischemia. PLoS One. 2016;11(6).

Yang B, Cai B, Deng P, Wu X, Guan Y, Zhang B, et al. Nitric oxide increases arterial endothelial permeability through mediating VE-cadherin expression during arteriogenesis. PLoS One. 2015;10(7).

Yoon SJ, Ko YG, Kim JS, Moon JY, Kim YJ, Park S, et al. Impact of coronary artery collaterals on infarct size assessed by serial cardiac magnetic resonance imaging after primary percutaneous coronary intervention in patients with acute myocardial infarction. Coron Artery Dis. 2009;20(5):440-5.

Zimarino M, D'andreamatteo M, Waksman R, Epstein SE, De Caterina R. The dynamics of the coronary collateral circulation. Nat Rev Cardiol. 2014;11(4):191-7.

Zhu H, Liang Y, Zuo T, Zhang M. The prognostic impact of the coronary collateral circulation in patients with coronary artery disease: A meta-analysis. Biomed Res (Special Issue Artificial Intelligent Techniques for Bio Medical Signal Processing Edition-I). 2017;158-66. 